\title{
EDITORIAL
}

\section{EL CONCEPTO DE LA SOLIDARIDAD}

Se describe que la palabra solidaridad proviene del latín soliditas, que expresa la realidad homogénea de algo físicamente entero, unido, compacto, cuyas partes integrantes son de igual naturaleza. Es posible encontrar diversos significados para este término tan conocido, que se define como: adhesión circunstancial a la causa o a la empresa de otros.

La teología cristiana adoptó el término solidaritas, aplicándolo a la comunidad de todos los hombres, iguales por ser hijos de Dios y vinculados estrechamente en sociedad. En este contexto, vemos que para la teología el concepto de solidaridad está estrechamente vinculado con el de fraternidad entre los hombres, que les impulsa a buscar el bien de todas las personas, sólo por el hecho de que todos son iguales en dignidad gracias a la filiación divina.

En el área del derecho, se entiende que los socios son solidarios cuando son individualmente responsables por la totalidad de las obligaciones. Jurídicamente, la solidaridad implica una relación de responsabilidad compartida, de obligación conjunta.

La doctrina social de la iglesia entiende la solidaridad como sinónimo de igualdad, fraternidad, ayuda mutua, en un todo unido a los conceptos de responsabilidad, generosidad, desprendimiento, cooperación y participación.

En estos tiempos, en que nuestro país está intentando volver a ponerse de piés después de un devastador terremoto, el valor de la solidaridad debiera invadirnos tanto en la dimensión humana como en el aspecto social y también profesional. Se trata de un concepto, un valor, una forma de enfrentar la relación con los demás que es eminentemente positiva porque evidencia el interés de cada uno de nosotros por el bien del prójimo.

La solidaridad se desprende de la naturaleza misma de la persona humana, indicando que los individuos no están solos, prefieren vivir acompañados porque el hombre, social por naturaleza, no puede prescindir de sus iguales ni tampoco intentar desarrollar sus capacidades de manera independiente.

En nuestra especialidad, los conceptos antes mencionados resultan de gran importancia, tanto para el desarrollo profesional de cada uno de nosotros como para la formación de los futuros especialistas y muy especialmente el bienestar de nuestros pacientes. 